\title{
Study on Humbleflies Species Biodiversity (Diptera: Bombyliidae) in the Western Margin of the Caspian Sea Coastline
}

\author{
Shirin AGHAVIRDINEZHAD ${ }^{1} \quad$ Alireza JALALI-ZAND ${ }^{2 *}$ \\ Department of Entomology, Faculty of Agriculture, Khorasgan (Isfahan) Branch, Islamic Azad \\ University, Isfahan, IRAN \\ e-mails: ${ }^{1}$ shirinaghavirdinezhad@yahoo.com, ${ }^{2 \star}$ arjalalizand@gmail.com

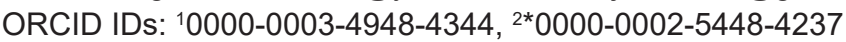

\begin{abstract}
In order to evaluate the Bombyliid species diversity in Guilan province, statistical sampling was performed from designated stations in the desired areas. Totally 20 species belonging to 11 genera were collected as below;

Callostoma soror Loew, 1873, Conophorus pseudaduncus Paramonov, 1929, Exoprosopa amseli Oldroyd, 1961, Exoprospora dispar Loew, 1869, Exoprosopa efflatounbeyi Paramonov, 1928, Exoprosopa grandis (Wiedemann in Meigen, 1820), Exoprosopa kirgizorum Paramonov, 1928, Exoprosopa pectoralis Loew, 1862, Hemipenthes subvelutinus Zaitzev, 1966, Heteralonia megerlie (Meigen, 1820), Heteralonia suffuse Klug, 1832, Thyridanthrax elegans (Wiedemann in Meigen, 1820), Thyridanthrax griseolus (Klug, 1832), Thyridanthrax punctum (Loew, 1854), Veribubo misellus, Loew 1869, Lomatia belzebul (Fabricius, 1794), Parageron lutescens (Bezzi, 1925), Usia bicolor Macquart, 1855, Phthiria pulicaria (Mikan, 1796) and Phthiria vagans Loew, 1846.

Most of the collected species were from the genus Exoprosopa Macquart, 1840 with relative frequency $54.83 \%$. According to Shanon-winner index 1.97 the highest species diversity was related to the Darestan region.
\end{abstract}

Key words: Biological control, Darestan region, Guilan province, Caspian sea, insects, pollination.

Aghavirdinezhad, S. \& Jalali-Zand, A. (2021). Study on humbleflies species biodiversity (Diptera: Bombyliidae) in the western margin of the Caspian sea coastline. Journal of the Entomological Research Society, 23(1), 61-67. 


\section{INTRODUCTION}

Diptera is considering as one of the major as well as biggest orders in insects classification, with great importance in several fields like agriculture, ecology and veterinary medicine (Ghafouri Moghaddam \& Gharali, 2014; Robertson et al, 2020). These insects have a variety of diets, including eating meat, vegetarianism, caries, and eating blood (Ramirez, 2018). From the biological pest control aspect, some families of diptera such as Tachinidae, Syrphidae, Cecidomyiidae are playing role as predator (Driesche \& Bellows, 1996). On the other hand, some species of families Sciaridae, Anthomyiidae, Cecidomyiidae and Tephritidae are considered as important agricultural pests (Latibari, Moravvej, Heller, Rulik, \& Namaghi, 2015).

The order diptera is divided into two sub-orders: Nematocera (mosquitoes) and Brachycera (flies). The Bombyliidae family is belonging to superfamily Asiloidea, suborder Brachycera (Evenhuis, 2002). The efficiency of some Bomyliidae species in biological control and IPM is remarkable. Most Bombyliids species are found in the Middle East and the Horn of Africa, where is native to migratory locusts (Hull, 1973). Most of Bombyliid species predating the locust's egg capsule, thus preventing their unnecessary outbreak (Shah, Godonou, Gbongboui, Hossou, \& Lomer, 1998). It is one of their beneficial roles in the natural regulation of these insects (Yeates \& Greathead, 1997). The Bombyliidae family devided to 100 genera included at least 45,000 described species worldwide. Unfortunately, there are few studies have been done on Bombyliidae family. However, more studies have been done in neighboring countries in Turkey, Oman, Iraq and Saudi Arabia (Greathead, 1980). Guilan province is located in the north part of Iran, in south-west margin of Caspian Sea, which is contain extensive green and first-class pastures with abundant vegetation (Akhani, Djamali, Ghorbanalizadeh, \& Ramezani, 2010) Since a serious study on Bombyliidae biodiversity has not been done in this region so far, it is expected to find interesting data about this family in the mentioned area. Due to the important role of most Bombyliidae species both in the pollination and natural regulation of pests, considering the high agricultural capacity in Guilan province, not only investigation on Bombyliid fauna but also the determination of their species diversity will be useful, as a basis for other related entomological studies about Bombyliidae in the similar ecological regions. The first principle in entomological studies is the investigation of insect fauna and biodiversity in the region, which is more than usual for Bombyliidae flies, due to their wide efficiency in biological pests control and IPM (Iperti, 1999).

\section{MATERIAL AND METHODS}

\section{Sampling and collection methods}

Sampling was done mainly from rangelands in different locations in Guilan province (Table 1 and Fig. 1). To collect larger species, flowering plants were sweeping net, especially plants such as ox-tongue flowers (to collect the Bombyliidae; Latreille, 1802 species). Other genera, due to their spawning behavior in areas free of vegetation on the soil, were collected during spawning using a net and used to collect smaller species. 
Bombyliidae Species Biodiversity in Iran

Table 1. Coordinates of sampling locations in Guilan province.

\begin{tabular}{|c|c|c|}
\hline Locality & Geographical Coordinates & Date \\
\hline Amlash & $37^{\circ} 5^{\prime} 29.88^{\prime \prime} \mathrm{N}, 50^{\circ} 11^{\prime} 12.98^{\prime \prime} \mathrm{E}$ & 2019.08.28, 2019.08.30 \\
\hline Bivarzen & $36^{\circ} 40^{\prime} 57.19^{\prime \prime} \mathrm{N}, 49^{\circ} 34^{\prime} 39.57^{\prime \prime} \mathrm{E}$ & 2019.04.17, 2019.04.21 \\
\hline Damash & $38^{\circ} 26^{\prime} 32.45^{\prime \prime} \mathrm{N}, 48^{\circ} 34^{\prime} 53.26^{\prime \prime} \mathrm{E}$ & 2019.06.26, 2019.06.29 \\
\hline Heiran Pass & $36^{\circ} 42^{\prime} 12.85^{\prime \prime} \mathrm{N}, 49^{\circ} 47^{\prime} 17.57^{\prime \prime} \mathrm{E}$ & 2019.05.27, 2019.05.31 \\
\hline Jirandeh & $36^{\circ} 48^{\prime} 34.96^{\prime \prime} \mathrm{N}, 49^{\circ} 24^{\prime} 57.98^{\prime \prime} \mathrm{E}$ & $2019.07 .23,2019.08 .20$ \\
\hline Rudbar- Darestan & $36^{\circ} 48^{\prime} 34.96^{\prime \prime} \mathrm{N}, 49^{\circ} 24^{\prime} 57.98^{\prime \prime} \mathrm{E}$ & 2019.08.07, 2019.08.09 \\
\hline Rudbar- Lockhee & $37^{\circ} 5^{\prime} 29.88^{\prime \prime} \mathrm{N}, 50^{\circ} 11^{\prime} 12.98^{\prime \prime} \mathrm{E}$ & 2019.06.04, 2019.06.07 \\
\hline Rustam Abad-Jokin & $36^{\circ} 40^{\prime} 57.19^{\prime \prime} \mathrm{N}, 49^{\circ} 34^{\prime} 39.57^{\prime \prime} \mathrm{E}$ & 2019.06.11, 2019.06.19 \\
\hline
\end{tabular}

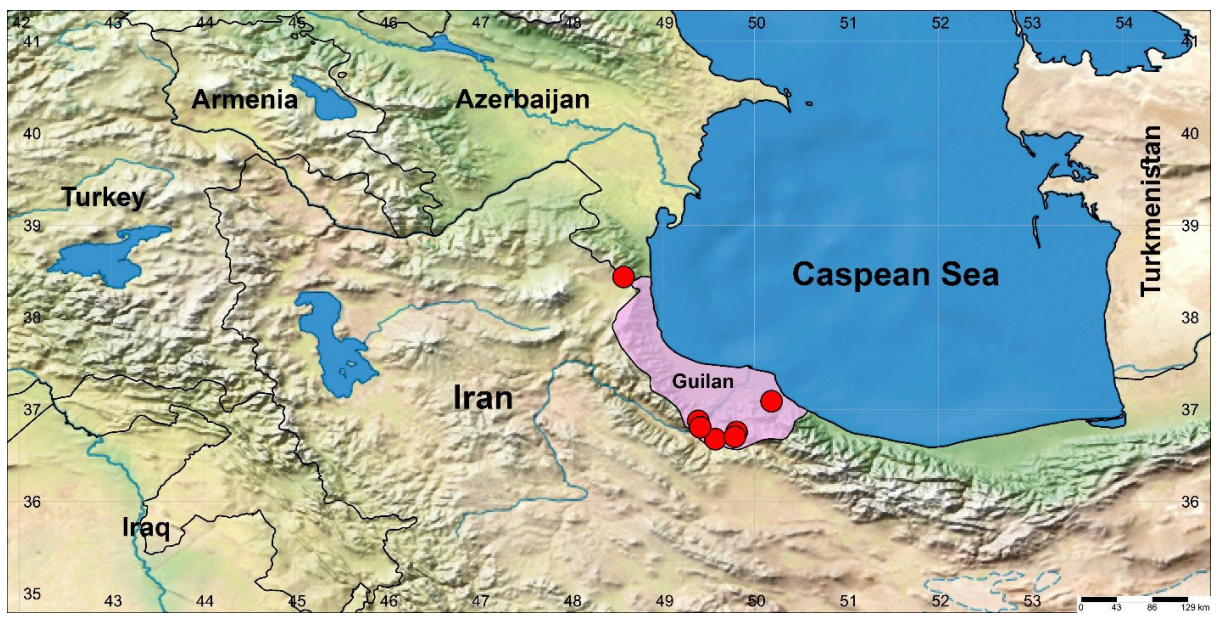

Fig. 1. The sampling localities in Guilan province.

\section{Preparation and storage of samples}

For larger species at the sampling site, to prevent hair loss and hair loss, they were killed with cyanide and these insects were cut with fine needles. Also, large species can be immersed in $96 \%$ alcohol and after transfer to the laboratory, they can be taken out of alcohol and dried and removed. For smaller species collected from pan traps, the samples were collected in $96 \%$ alcohol after collection from traps and stored in the freezer.

\section{Species identification}

The available scientific sources; Paramonov (1928), Engel (1932-1937), Zaitzev (1966), Linder (1975) and Greathead \& Evenhuis (2001) have been consulted to identify species. The identifications have been confirmed by Dr. Rahim Abdollahi Mesbah (University of Tehran). 


\section{Statistical analysis}

All of collected insets were sorted out according to their species/location. Their frequency data were analysed using Shannon's Weiner diversity index to compare abundance and species richness among different localities in the study areas.

\section{RESULT AND DISCUSSION}

Totally 20 species belong 11 genera were collected, identified and illustrated (Table 2). According to dynamic populations of collected samples, $P$. vagans with the highest occurrence frequency between collected flies, is considered as dominant species (Fig. 2). Also, the highest species biodiversity index; Shanon-winner have been seen in Darestan station (Fig. 3).

Table 2. Species frequency/Shanon-winner index in each location.

\begin{tabular}{|c|c|c|c|c|c|c|c|c|}
\hline Species & Amlash & Bivarzen & Damash & $\begin{array}{l}\text { Locations } \\
\text { Heiran Pass }\end{array}$ & Jirandeh & Rudbar-Darestan & Rudbar- Lockhee & Rustam Abad-Jokin \\
\hline Exoprosopa amseli & & & & & 3 & 7 & & 3 \\
\hline E. kirgizorum & & & & & 6 & & & 15 \\
\hline E. efflatounbeyi & & & & & & 4 & & \\
\hline E. pectoralis & & & & & & & 3 & \\
\hline E. grandis & & & & & & 1 & & \\
\hline E. dispar & & & & & 2 & & & 2 \\
\hline Thyridanthrax punctum & & & & & & 1 & & \\
\hline T. elegans & 8 & & 4 & & & & & \\
\hline T. griseolus & & & & & & 6 & & \\
\hline Lomatia belzebul & & & 5 & & & & & \\
\hline Usia bicolor & 25 & & & 40 & & 5 & & \\
\hline Parageron lutescens & & & & & & & 1 & \\
\hline Conophorus pseudaduncus & & & & 1 & & & & \\
\hline Heteralonia megerlie & & & & 1 & & & & \\
\hline H. suffuse & & & & & & & 3 & \\
\hline Callostoma soror & 5 & & & & & & & \\
\hline Veribubo misellus & & & & & & 3 & & \\
\hline Hemipenthes subvelutinus & & & & & 10 & 2 & & 6 \\
\hline Phthiria vagans & 20 & 100 & 100 & 30 & 20 & 10 & 20 & 10 \\
\hline Phthiria pulicaria & & & & 1 & & & & \\
\hline Shanon Winner index & 0 & 0.67 & 0.83 & 1.38 & 0.79 & 1.31 & 1.97 & 1.21 \\
\hline
\end{tabular}

The results showed that the highest and lowest densities and biodiversity of Bombyliid flies in sampling related to Guilan province, in the western margin of the Caspian Sea coastline. The Bombyliid species are placed as important members of 
Bombyliidae Species Biodiversity in Iran

biodiversity, playing an impressive role in the natural ecosystem counterbalance; as partly primary consumers, an essential part of food-chains with predation pests, and mostly with pollination. even though there are exerting unprecedented pressures like human-made ones, on ecosystems all over the world, and such pressures may affect all the species (El-Hawagry \& Gilbert, 2014).

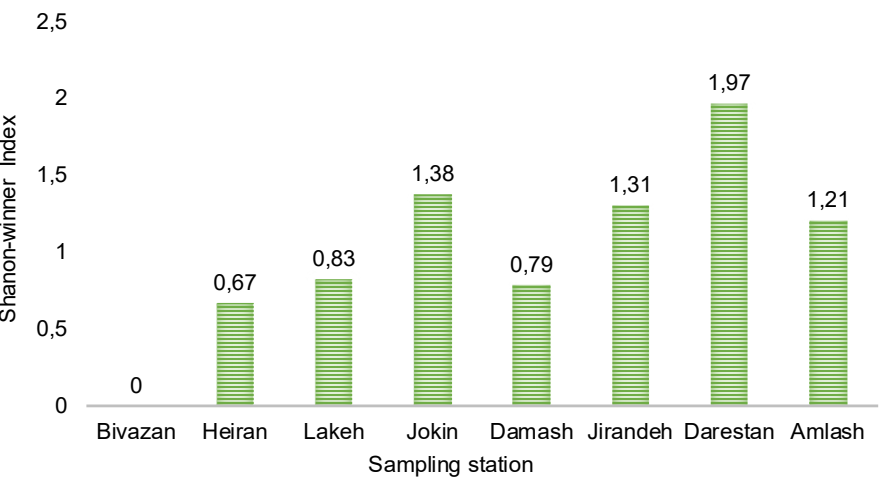

Fig. 2. Relative frequency for each species.

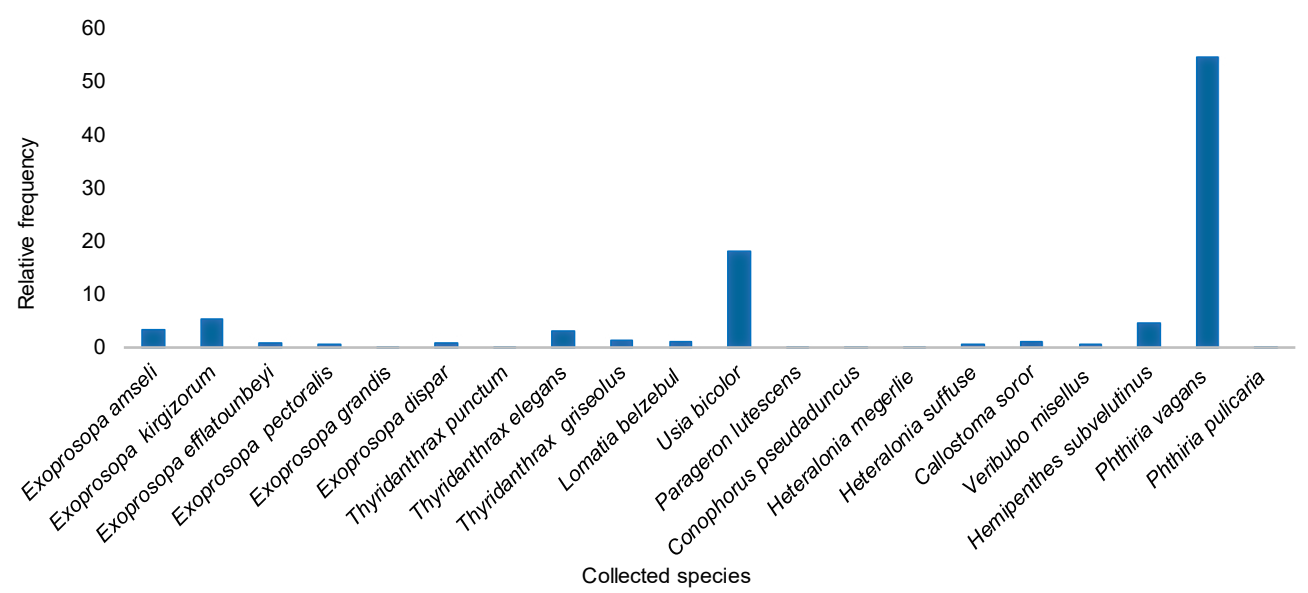

Fig. 3. Shanon-Winner Index amount for each station.

The greatest threats to beneficial insects (natural enemies) are habitat fragmentation and destruction, intensification of agricultural practice with over-use of pesticides and herbicides which is the main reason for increasing the pests population by supporting their resistance to their control methods (Tschumi et al, 2016; Heidari Latibari, Moravej, Ghafouri Moghaddam, Barahoei, \& Hanley, 2020). Despite Guilan province being known for its rich biological diversity in flora and fauna, but the preservation of its habitats have received scant attention. Nevertheless, most of its biodiversity, including Bombyliidae species, is still unexplored because of a significant lack of 
national research capacity. This study has substantially increased the knowledge of Bombyliidae diversity in an important agricultural region in Iran. Previous studies have listed limited species of the present species in Iran. However, the number of species found in our study was so lower than in comparable studies outside of Iran. This most likely reflects the region's relatively low diversity of this family. Based on our own results. Aim to increase our biodiversity knowledge about insect fauna, especially on beneficial groups like Bombyliidae, capacity building in the area at various levels is needed. we hypothesize that the diversity of Bombyliidae in the agroecosystems is substantially higher than is currently known. Lack of specialists and organized projects on insect biodiversity in the margin of the Caspian Sea, are among the identified gaps.

\section{ACKNOWLEDGEMENTS}

The authors would like to thank anonymous reviewers for their helpful comments aim to improve this article. The authors have gratefully acknowledged the financial support from Islamic Azad University (Khorasgan Branch).

\section{REFERENCES}

Akhani, H., Djamali, M., Ghorbanalizadeh, A., \& Ramezani, E. (2010). Plant biodiversity of Hyrcanian relict forests, $\mathrm{N}$ Iran: an overview of the flora, vegetation, palaeoecology and conservation. Pakistan Journal of Botany, 42(1), 231-258.

Driesche, R.G. \& Bellows, T.S. (1996). Parasitoids and predators of Arthropods and Molluscs. Biological control (pp. 37-65). Springer, Boston, MA.

El-Hawagry, M. \& Gilbert, F. (2014). Zoogeographical affinities and faunal relationships of bee flies (Diptera: Bombyliidae) in Egypt. Zoology in the Middle East, 60(1), 50-56.

Engel, E.O. (1932-1937). Bombyliidae. In E. Lindner (Ed.). Die Fliegen der Palaearktischen Region. Schweizerbart, Bd. IV, (3), Stuttgart, 619 pp.

Evenhuis, N.L. (2002). Catalog of the Mythicomyiidae of the world (Insecta: Diptera). Bishop Museum Press, $85 \mathrm{pp}$.

Ghafouri Moghaddam, M. \& Bharali, B. (2014). First record of Leucopis (Leucopis) spyrothecae (Dip.: Chamaemyiidae) from Iran. Journal of Entomological Society of Iran, 34(2), 53-54.

Greathead, D.J. (1980). Insects of Saudi Arabia. Diptera: Fam. Bombyliidae. Fauna of Saudi Arabia, 2, 291-337.

Greathead D.J. \& Evenhuis, N.L. (2001). Annotated keys to the genera of African Bombylioidea (Diptera: Bombyliidae: Mythicomyiidae). African Invertebrates, 42, 105-224.

Heidari Latibari, M., Moravej, G., Ghafouri Moghaddam, M., Barahoei, H., \& Hanley, G.A. (2020). The novel host associations for the aphid parasitoid, Pauesia hazratbalensis (Hymenoptera: Braconidae: Aphidiinae). Oriental Insects, 54(1), 88-95.

Hull, F.M. (1973). Bee flies of the world: the genera of the family Bombyliidae. Smithsonian Institution Press, Washington, D.C., 687 pp.

Iperti, G. (1999). Biodiversity of predaceous coccinellidae in relation to bioindication and economic importance. Agriculture, Ecosystems \& Environment, 74(1-3), 323-342.

Latibari, M.H., Moravvej, G., Heller, K., Rulik, B., \& Namaghi, H.S. (2015). New records of Black Fungus Gnats (Diptera: Sciaridae) from Iran, including the reinstatement of Bradysia cellarum Frey. Studia Dipterologica, 22(1), 39-44. 
Bombyliidae Species Biodiversity in Iran

Linder, E. (1975). Bombyliidae ausdem Iran (Diptera). Stuttgarter Beiträgezur Naturkunde, 275, 1-19.

Paramonov, S.J. (1928). Beitragezur monographie der gattung exoprosopa. Trudy Fizychno-Matematychnogo Viddil Ukrains'ka Akademiya Nauk, 6(2), 181-303.

Robertson, A.R., Finch, J.T., Young, A.D., Spooner-Hart, R.N., Outim, S.K., \& Cook, J.M. (2020). Species diversity in bee flies and hover flies (Diptera: Bombyliidae and Syrphidae) in the horticultural environments of the Blue Mountains, Australia. Austral Entomology, 59(3), 561-571.

Ramirez, I. (2018). Philornis Downsi Interactions with its Host in the Introduced Range and its Parasitoids in its Native Range. Master Thesis, The University of Minnesota.

Shah, P.A., Godonou, I., Gbongboui, C., Hossou, A., \& Lomer, C.J. (1998). Survival and mortality of grasshopper egg pods in semi-arid cereal cropping areas of northern Benin. Bulletin of Entomological Research, 88(4), 451-459.

Tschumi, M., Albrecht, M., Collatz, J., Dubsky, V., Entling, M.H., Najar-Rodriguez, A.J., \& Jacot, K. (2016). Tailored flower strips promote natural enemy biodiversity and pest control in potato crops. Journal of Applied Ecology, 53(4), 1169-1176.

Yeates, D.K., \& Greathead, D. (1997). The evolutionary pattern of host use in the Bombyliidae (Diptera): a diverse family of parasitoid flies. Biological Journal of the Linnean Society, 60(2), 149-185.

Zaitzev, V.F. (1966). Parasitic flies of the family Bombyliidae (Diptera) in the fauna of Transcaucasia. Nauka, Moscow and Leningrad, USSR, 375 pp. [in Russian] 